\title{
HUBUNGAN TINGKAT PENGETAHUAN PESERTA DIDIK PUTRI DI SMAN 6 BULUKUMBA KELAS X DENGAN KEJADIAN DISMENOREA KECAMATAN HERLANG KABUPATEN BULUKUMBA
}

\author{
Jusni*, Akhmad rivandi, Erniawati, Lili Andriani, Mudyawati Kamaruddin \\ Program Studi Kebidanan, Akademi Kebidanan Tahirah Al Baeti Bulukumba, Sulawesi Selatan \\ *Corresponding author: Telp: +6285256904894, email: unhy.ijazn@gmail.com
}

\begin{abstract}
ABSTRAK
Permasalahan kesehatan reproduksi di kalangan remaja putri yang berkaitan dengan gangguan menstruasi atau dismenorea masih cukup tinggi. Berdasarkan data WHO (World Health Organization) kejadian dismenorea di dunia rata-rata 50\% sedangkan di Indonesia sebesar $64,25 \%$ yang mengalami dismenorea. Tujuan penelitian ini adalah untuk mengetahui angka kejadian dismenorea pada peserta didik putri di SMA Negeri 6 Bulukumba kelas X dan untuk mengetahui hubungan tingkat pengetahuan peserta didik putri di SMA Negeri 6 Bulukumba kelas $\mathrm{X}$ dengan kejadian dismenorea. Penelitian ini merupakan penelitian deskriftif, rancangan yang di gunakan adalah Cross Sectional, yaitu sampel penelitian yang diamati pada waktu yang sama. Hasil yang diperoleh adalah hampir semua siswa mempunyai pengetahuan cukup baik dari kelompok yang mengalami Dismenorea $(89,2 \%)$, maupun siswa yang tidak mengalami Dismenorea $(54,5 \%)$. Siswa yang berpengetahuan baik didominasi pada kelompok yang tidak mengalami dismenorea (42.4\%), sedangakn pada kelompok dismenorea hanya $2.7 \%$. Sebaliknya siswa yang berpengetahuan kurang, didominasi pada kelompok dismenorea yaitu $8,1 \%$, dan 3.0\% dari kelompok siswa yang tidak mengalami dismenorea. Berdasarkan hasil Chi square bahwa ada hubungan antara pengetahuan peserta didik putri dengan kejadian dismenorea dengan nilai $0.001<0,05$.
\end{abstract}

Kata kunci : Peserta Didik Putri, Pengetahuan, Dismenorea

\section{ABSTRACT}

Reproductive health problems among young women due to menstrual disorders or dysmenorrhea are still quite high. Based on data from the World Health Organization, the incidence of dysmenorrhea in the world is on average 50\%, whereas the incidence of dysmenorrhea in Indonesia is 64.25\%. This research aim is to determine the incidence of dysmenorrhoea in female students at SMA Negeri 6 Bulukumba class $X$ and to determine the relationship between the level of awareness and the incidence of dysmenorrhoea of female students at SMA Negeri 6 Bulukumba class X. This analysis is a descriptive, cross-section design study in which the research sample is studied at the same time. The findings obtained were that almost all students had ample knowledge of the dysmenorrhoea community (89.2\%) and the students who did not experience in dysmenorrhea (54.5\%). Students with strong awareness were dominated by the dysmenorrhoea-free community (42.4\%), while the dysmenorrhoea group was just $2.7 \%$. On the other hand, students who lacked knowledge were dominated by the dysmenorrhoea community, namely $8.1 \%$, and $3.0 \%$ of students who did not experience dysmenorrhoea. Based on the effects of the Chi square, there is a relationship between the knowledge of female students and the occurrence of dysmenorrhoea at a value of $0.001<0.05$.

Keywords: Female Students, Knowledge, Dysmenorrhoea

\section{PENDAHULUAN}

Masa remaja (Adolescence) adalah masa transisi atau peralihan dari masa kanak-kanak menuju dewasa yang ditandai adanya perubahan fisik, psikis dan psikososial. Remaja tidak hanya tumbuh menjadi lebih tinggi dan lebih besar akan tetapi juga terjadi perubahan-perubahan di dalam tubuh yang 
memungkinkan untuk bereproduksi ${ }^{1}$. Indonesia sebagai negara berkembang mempunyai penduduk usia remaja yang cukup besar. Berdasarkan hasil sensus penduduk tahun 2010, jumlah remaja Indonesia usia 10-24 tahun sekitar 67 juta atau $29 \%$ dari total seluruh populasi (Badan Pusat Statistik, 2016). Sedangkan berdasarkan data Kemenkes RI tahun 2016, jumlah remaja putri di Indonesia sebesar $16 \%$ pada tahun $2015^{2}$.

Salah satu perubahan yang terjadi ketika menuju dewasa pada remaja putri adalah terjadinya menstruasi. Menstruasi adalah perdarahan dari uterus yang terjadi secara periodik dan siklik. Hal ini disebabkan karena pelepasan (Deskuamasi) endometrium akibat hormon ovarium (Estrogen dan Progesteron) mengalami penurunan terutama progesteron, pada akhir siklus ovarium, biasanya dimulai sekitar 14 hari setelah ovulasi. Meskipun menstruasi ialah proses alamiah yang dialamih oleh perempuan, hal ini menjadi masalah utama dalam masyarakat jika terjadi gangguan menstruasi. ${ }^{3}$ Namun salah satu yang cukup mengkhawatirkan dikalangan remaja putri adalah gangguan menstruasi yaitu dismenorea. Berdasarkan data WHO (world health organization) angka kejadian dismenorea di dunia sangat besar rata-rata dari $50 \%$ perempuan disetiap negara mengalami nyeri haid. Kejadian dismenorea di Indonesia sebesar 64,25\% yang terdiri dari $54,89 \%$ dismenorea primer dan dan 9,36\% dismenorea sekunder. Dismenorea primer dialami oleh 60-75 \% remaja dengan tiga perempat dari jumlah remaja tersebut mengalami nyeri ringan dan seperempat lagi mengalami nyeri berat. ${ }^{4}$

Sampai saat ini kesehatan reproduksi masih merupakan masalah kesehatan masyarakat di Indonesia. Termasuk dikalangan remaja putri, permasalahan kesehatan reproduksi remaja putri berkaitan dengan gangguan menstruasi yaitu dismenorea. Dismenorea disebut juga kram menstruasi atau nyeri menstruasi, dalam bahas inggris, dismenorea disebut sebagai "painful period" atau menstruasi yang menyakitkan. Nugroho dan Utama (2014) mengatakan dismenorea apabila tidak segera diatasi akan mempengaruhi fungsi mental dan fisik individu sehingga mendesak untuk segera mengambil tindakan terapi secara farmakologis atau nonfarmakologis ${ }^{5}$. Beberapa hal yang dapat dilakukan untuk mengatasi nyeri menstruasi yaitu kompres air hangat tepat pada bagian yang terasa kram, minum minuman hangat yang mengandung kalsium tinggi, menggosok-menggosok daerah yang nyeri, ambil posisi menungging sehingga rahim tergantung kebawah dan tarik nafas secara perlahan-lahan untuk relaksasi ${ }^{6}$. Hampir semua wanita mengalami rasa tidak enak pada saat menstruasi. Namun istilah dismenorea hanya dipakai bila nyeri begitu hebat sehingga mengganggu aktivitas dan memerlukan obar-obatan. ${ }^{7}$ Namun beberapa faktor yang dapat mempengaruhi terjadinya dismenorea yaitu ketidak seimbangan hormon yang disebabkan karena tingginya kadar prostaglandin, dan faktor psikologisnya ${ }^{8}$. Faktor internal yang terpenting adalah kopin individu, pendidikan, dan koknitif. Pengetahuan yang lebih baik akan lebih membantu remaja putri dalam koping akibat dismenorea sehingga kualitas hidup lebih baik ${ }^{9}$.

Kejadian dismenorea masih cukup tinggi namun masih sedikit remaja putri yang mencari informasi yang timbul saat menstruasi dan dampaknya ${ }^{4}$. Adanya kepercayaan dan budaya tabu membicarakan tentang menstruasi juga menghambat remaja putri untuk mencari informasi mengenai menstruasi dan permasalahannya, khususnya terkait dismenorea. Informasi tentang menstruasi dan permasalahannya penting dalam perkembangan pelayanan kesehatan reproduksi bagi remaja putri. Sikap yang ditunjukkan remaja putri tergantung pengetahuan yang dimiliki. Pengetahuan tentang dismenorea dapat membantu dalam mengatasi dismenorea. Remaja putri yang mendapatkan informasi yang benar tentang dismenorea maka mereka akan mampu mengatasi dismenorea. Sebaliknya remaja yang kurang pengetahuannya tentang dismenorea akan merasa cemas dan stres 
yang berlebihan dalam menghadapi dismenore. $^{10}$

Kejadian dismenorea di SMA Negeri 6 Bulukumba pada survey awal pada tanggal 25 desember 2019, terdapat 10 peserta didik putri yang mengalami nyeri haid (Dismenorea). Dari hasil survey awal terdapat beberapa remaja yang merasa cemas dengan nyeri yang dirasakan saat menstruasi, khawatir nyeri yang dirasakan saat menstruasi dapat menyebabkan mandul setelah menikah, khawatir ada kelainan dalam rahim. Nyeri yang dirasakan pada saat menstruasi menghambat aktivitas sekolah. Tindakan yang dilakukan dalam penanganan dismenorea dengan cara mengonsumsi obatobatan. Beberapa diantara responden tidak pernah mendapatkan informasi terkait dismenorea.

Berdasarkan latar belakang tersebut, belum dapat dipastikan hubungan tingkat pengetahuan remaja putri tentang kejadian dismenorea di SMA Negeri 6 Bulukumba, sehingga peneliti tertarik untuk melakukan penelitian yang bertujuan untuk mengetahui hubungan tingkat pengetahuan peserta didik putri di SMA Negeri 6 Bulukumba kelas X dengan kejadian dismenorea

\section{METODOLOGI}

Jenis penelitian yang digunakan adalah survey deskriftif, Populasi dalam penelitian ini adalah peserta didik putri di SMA Negeri 6 Bulukumba kelas $\mathrm{X}$ dengan populasi sebanyak 154 siswi. Teknik pengambilan sampel ini adalah accidental sampling. sebanyak 70 responden (100\%) dari populasi. Jenis data yang dikumpulkan dalam penelitian ini adalah primer dan sekunder. Pengumpulan data primer dilakukan dengan cara mengisi kuesioner. Dalam penelitian ini adalah hubungan pengetahuan peserta didik putri kelas $\mathrm{X}$ dengan kejadian dismenorea Pengumpulan data sekunder diperoleh di SMA Negeri 6 Bulukumba. Dalam penelitian ini yang menjadi variabel dependent yaitu pengetahuan tentang dismenorea dan independant yaitu kejadian dismenorea.

\section{HASIL DAN PEMBAHASAN \\ HASIL}

\section{Analisis Univariat}

Tabel 1 Ditribusi Responden Berdasarkan Kejadian Dismenorea

\begin{tabular}{lll}
\hline Dismenorea & $\mathrm{F}$ & $\%$ \\
\hline YA & 37 & 52,9 \\
TIDAK & 33 & 47,1 \\
\hline Total & 70 & 100,0 \\
\hline
\end{tabular}

Berdasarkan tabel 1 diketahui bahwa dari 70 responden, menunjukkan bahwa yang mengalami dismenorea lebih tinggi yaitu $52,9 \%$ dibandingkan dengan yang tidak mengalami dismenorea sebanyak 47,1\%.

Tabel 2 Distribusi frekuensi pengetahuan peserta didik putri dengan kejadian dismenorea

\begin{tabular}{lll}
\hline Pengetahuan & Jumlah & Presentase \\
\hline Baik & 14 & $20,0 \%$ \\
Cukup & 52 & $74,3 \%$ \\
Kurang & 4 & $5,7 \%$ \\
\hline Total & 70 & 100,0 \\
\hline
\end{tabular}

Setelah dilakukan penelitian di SMAN 6 Bulukumba tahun 2020 dan pengolahan data diperoleh hasil, bahwa dari 70 peserta didik putri yang berpengetahuan baik sebanyak 14 $(20,0 \%)$, peserta didik putri yang berpengetahuan cukup sebanyak 52 (74,3\%), dan peserta didik putri yang berpengetahuan kurang sebanyak $4(5,7 \%)$.

\section{Analisis Bivariat}

Tabel 3 Distribusi hubungan pengetahuan peserta didik putri dengan kejadian dismenorea

\begin{tabular}{|l|l|l|l|l|l|}
\hline Dismenore & \multicolumn{3}{|c|}{ PENGETAHUAN } & Total & $\begin{array}{l}\text { P } \\
\text { value }\end{array}$ \\
\hline Dismenore & 1 & 33 & 3 & 37 & \\
\hline & $2,7 \%$ & $89,2 \%$ & $8,1 \%$ & $100 \%$ & \multirow{2}{*}{0,001} \\
\cline { 1 - 5 } $\begin{array}{l}\text { Tidak } \\
\text { dismenor }\end{array}$ & 14 & 18 & 1 & 33 & \\
\cline { 1 - 5 } & $42,4 \%$ & $54,5 \%$ & $3,0 \%$ & $100 \%$ & \\
\hline Total & 15 & 51 & 4 & 70 & \\
\hline & 21,4 & 72,9 & $5,7 \%$ & $100 \%$ & \\
\hline
\end{tabular}

Dari tabel 3 dapat dilihat bahwa yang berpengetahuan cukup yang dismenorea yaitu 
$89,2 \%$ dan tidak dismenorea yaitu 54,5\%, $8,1 \%$ berpengetahuan kurang yang dismenorea dan $3 \%$ yang tidak dismenorea, sedangkan yang berpengetahuan baik 2,7 \% yang dismenorea dan $42,4 \%$ yang tidak dismenorea. Hasil uji kai kuadrat menunjukkan ada hubungan (0,001); peserta didik putri yang berpengetahuan cukup dan mengalami dismenorea adalah 89,2 \% dan $42,4 \%$. Peserta didik putri berpengetahuan baik yang tidak mengalami dismenorea dan jika $p>0,05$ berarti tidak ada hubungan antara pengetahuan peserta didik putri dengan kejadian dismenorea. Dengan demikian dapat dinyatakan bahwa ada hubungan antara pengetahuan peserta didik putri dengan kejadian dismenorea.

\section{PEMBAHASAN}

\section{Kejadian dismenorea}

pada penelitian ini yang menjadi responden adalah peserta didik putri di SMAN 6 Bulukumba. Hal ini sesuai dengan pendapat Soekanto (2014) menyatakan bahwa peserta didik putri adalah wanita yang berusia 13 sampai 17 tahun serta ditandai dengan perkembangan spiritual dan badaniah. pada peserta didik putri terjadi suatu perubahan fisik yaitu perubahan organ-organ reproduksi yang ditandai dengan datangnya menstruasi (Kumalasari dan Andhyantoro, 2012). Namun saat menstruasi, kadang remaja mengalami dismenorea, dismenorea adalah nyeri perut yang berasal dari kram rahim dan terjadi selama menstruasi. ${ }^{11}$

Hasil penelitian diketahui bahwa dari 70 responden ternyata di peroleh data terkait angka kejadian dismenorea lebih banyak yaitu 52,9\% dibandingkan yang tidak dismenorea yaitu $47,1 \%$. Kondisi tersebut menunjukkan lebih dari 50\% responden yang mengalami dismenorea atau nyeri menstruasi berlebihan. Dari 70 peserta didik putri yang jadi responden, terdapat 37 responden mengaku mengalami dismenorea atau nyeri haid, 33 orang yang tidak mengalami dismenorea saat menstruasi.

Pengetahuan remaja tentang kesehatan reproduksi sangat penting terhadap tindakan pencegahan dan penanganan dalam mengurangi kejadian dismenorea. Hasil penelitian di dapatkan dari 70 responden yang berpengetahuan cukup lebih banyak yaitu $74,3 \%$ di bandingkan dengan yang berpengetahuan baik yaitu $20 \%$, sedangkan yang berpengetahuan kurang 5,7 \% tentang dismenorea.

\section{Hubungan Pengetahuan Peserta Didik Putri Tentang Dismenorea}

Pengetahuan peserta didik putri tentang dismenorea di SMAN 6 Bulukumba. sebagian besar berada pada kategori cukup. Hal ini menyatakan bahwa peserta didik putri di SMAN 6 Bulukumba masih membutuhkan informasi tentang dismenorea. Hal ini sangat dimungkinkan karena sebagian besar peserta didik putri belum menperoleh informasi tentang dismenorea. Walaupun beberapa remaja yang telah mendapatkan informasi mengenai dismenorea dari berbagai sumber namun informasi yang diperoleh peserta didik putri belum mampu dimengerti oleh peserta didik putri. Dari hasil penelitian yang dilakukan didapatkan bahwa ada hubungan angka kejadian dismenorea dengan pengetahuan peserta didik putri tentang dismenorea di SMAN 6 Bulukumba dengan hasil uji kai kuadrat menunjukkan ada hubungan $(0,001)$; peserta didik putri yang berpengetahuan cukup dan mengalami dismenorea adalah $89,2 \%$ dan $42,4 \%$ peserta didik putri berpengetahuan baik yang tidak mengalami dismenorea. Hasil penelitian ini sesuai dengan penelitian. ${ }^{12}$ bahwa sebagian besar pengetahuan peserta didik putri tentang dismenorea adalah cukup yang meliputi pengertian, penyebab dan penanganan dismenorea.

Peserta didik putri yang memiliki pengetahuan yang kurang akan cenderung mengabaikan kesehatan dan pada akhirnya akan memiliki tindakan yang akan membahayakan bagi dirinya sendiri. Peserta didik putri yang memiliki pengetahuan kurang tentang dismenorea akan memilih perilaku yang kurang tepat untuk penanganan dan pencegahan gangguan menstruasi berupa dismenorea. $^{13}$ Kondisi tersebut diperparah dengan kurangnya pengetahuan karena 
adanya anggapan atau persepsi yang salah tentang kesehatan reproduksi khususnya terkait dismenorea. Demikian pula hasil penelitian, ${ }^{1,4}$ yang menyimpulkan ada hubungan yang signifikan antara tingkat pengetahuan peserta didik putri dengan perilaku penanganan dismenorea.

Sedangkan penelitian Gozali (2015) menyatakan hal yang sebaliknya bahwa sebagian besar pengetahuan peserta didik putri tentang dismenorea adalah baik. Pengetahuan merupakan hasil tahu yang terjadi setelah orang melakukan penginderaan terhadap suatu objek tertentu. ${ }^{9,15}$ Dalam penelitian Gozali lembar yang digunakan untuk mengukur pengetahuan peserta didik putri yaitu lembar teks yang dimana diketahui bahwa lembar teks yaitu menceklis ya / tidak sedangkan yang saya gunakan yaitu lembar kuesioner.

\section{KESIMPULAN}

Dari hasil penelitian dan pembahasan tentang prevalensi dan hubungan tingkat pengetahuan peserta didik putri di SMAN 6 Bulukumba kelas $\mathrm{X}$ dengan kejadian dismenorea dapat disimpulkan sebagai berikut :

1. Dari 70 responden yang diteliti di SMAN 6 Bulukumba di temukan peserta didik putri yang mengalami dismenorea terdapat 37 responden dan yang tidak mengalami dismenorea atau nyeri haid 33 responden saat menstruasi.

2. Dari 70 peserta didik putri yang berpengetahuan baik sebanyak 14 $(20,0 \%)$, peserta didik putri yang berpengetahuan cukup sebanyak 52 $(74,3 \%)$, dan peserta didik putri yang berpengetahuan kurang sebanyak 4 $(5,7 \%)$

3. Setelah dilakukan uji statistic menggunakan uji Chi Square diperoleh nilai $\mathrm{p}<0,05$ berarti ada hubungan antara pengetahuan peserta didik dengan kejadian dismenorea dan jika nilai p>0,05 berarti tidak hubungan antara pengetahuan peserta didik putri dengan kejadian dismenorea. Dengan demikian dapat dinyatakan bahwa ada hubungan antara pengetahuan peserta didik putri dengan kejadian dismenorea.

\section{DAFTAR PUSTAKA}

1. Felicia, Hutagaol E, Kundre R. Hubungan Status Gizi dengan Siklus Menstruasi pada Remaja Putri di PSIK FK UNSRAT Manado. e-Kp. 2015;3(1).

2. Kementerian Kesehatan RI Badan Litbangkes. Laporan Kinerja Litjen Kesehatan Masyarakat. Published online 2016.

3. Kusmiran. Kesehatan Reproduksi Remaja Dan Wanita. Salemba Medika; 2014.

4. Kamaruddin M, Haerani, Ningsih S, Anjeli AMR. Deskripsi Pengetahuan Remaja Putri tentang Dismenore di Kelurahan Benjala Kecamatan Bontobahari Kabupaten Bulukumba. FK UNISA Palu. 2020;2(2):197-206. doi:10.31219/osf.io/qf4yu

5. Nugroho T, Utama BI. Masalah Kesehatan Reproduksi Wanita. Nuha Medika; 2014.

6. Galuh RT. Hubungan Pengetahuan Remaja Putri tentang Dismenorea dengan Penanganan Dismenorea. Politek Kementeri Kesehat. Published online 2018.

7. Sukarni I, Margareth ZH. Buku Ajar Keperawatan Maternitas. Nuha Medika; 2013.

8. Dewi N. Biologi Reproduksi. Yogyakarta. Pustaka Rihama; 2018.

9. Hartati. Mekanisme Kopin Mahasiswi Keperawatan dalam menghadapi Dismenorea. Poltekes Semarang. 2012;8(1).

10. Benson M. Buku Saku Ilmu Kebidanan, Buku Petunjuk Praktis Untuk Mahasiswa Kedokteran, Perawat Dan Parademic Serta Resident. Binapura Aksara; 2014.

11. Notoatmodjo S. Metodologi Penelitian Kesehatan. Rineka Cipta; 2014.

12. Linawati. Hubungan Pengetahuan dan Sikap Remaja Putri dengan Penanganan Dismenorea di SMA 10 Kendari. Published online 2017. 
13. Marni. Kesehatan Reproduksi. Pustaka Pelajar; 2015.

14. Eka HY. Factor-Faktor Yang Berhubungan Dengan Nyeri Menstruasi (Dismenorea) Pada Remaja Putri Di Beberapa Sma Di Kabupaten Rokan Hulu. Jurnal Maternity Dan Neonatal. 2014;1(4).

15. Lestari NMSD. Pengaruh Dismenorea pada Remaja Semin Nas FMIPA UNDIKSHA III. Published online 2013:323-329. 